\title{
PRACTICAL POINTS ON PRIVATE NURSING
}

\author{
IN ChaRGE OF
}

ISABEL McISAAC

\section{CONVENIENT DIET-LISTS FOR PRIVATE DUTY NURSES}

THE introduction of dietetics as a part of the pupil nurse's class work was a long stride in the right direction; but-there is always a but or an if-the step was not long enough, and many nurses find themselves under varying circumstances puzzling over the classification of foods, and wishing for convenient lists which would save a tired, hurried nurse from trying to conjure up what she used to know about the chemistry of foods.

If the diet lessons extended over the full course of training, or the pupil nurse took a long course in a regular cooking-school, the difficulty might be altogether overcome, but at present this is not practicable in most schools, and many a nurse is worried and harassed, not by not knowing how to cook, but by not knowing what to cook.

This question was one of interest to a nurse who spent much time and many inquiries trying to find something which would be at once practical, definite, and valuable.

Long lists of medical books were gone over, doctors invoked for suggestions, clerks in medical book-stores consulted, all without a glimmer of an idea, until upon a lucky day, aimlessly looking over a table full of medical books while waiting for a package, a thin, brown volume, closely resembling an exaggerated bank check-book, bearing the title "DietLists and Sick-Room Dietary. Thomas," was found. Inside, the book was called "A Book of Detachable Diet-Lists for Albuminuria, Anæmia and Debility, Constipation, Diabetes, Diarrhœa, Dyspepsia, Fevers, Gout or Uric Acid Diathesis, Obesity, Tuberculosis, and a Sick-Room Dietary, compiled by Jerome B. Thomas, A.B., M.D." These lists, which Dr. Thomas "offers to the medical profession as a practical aid to the better practice of therapeutics," are equally practical and valuable to nurses. They come in groups, with a key, that the doctor may tear out the one suited to a particular case and leave it with the family or nurse. The book in its present shape is not convenient for nurses, and the per- 
mission of the publisher, W. B. Saunders, of Philadelphia, was kindly given to print the lists in this form for the use of nurses.

The Sick-Room Dietary is partly omitted.

\section{ALBUMINURIA}

Generat Rules.

Take readily-assimilable foods that leave a small amount of nitrogenous waste-matters to be eliminated by the kidneys. Danger in overfeeding.

\section{MAY TAKE:}

Soups.-Arrowroot soup with onions, milk soups with rice, tapioca, or vermicelli.

Fish.-Fresh white fish, raw oysters, clams.

Meats (very little).-Very little red meats, mostly the white kinds; chicken, game, fresh pork, bacon, calf's head, ham.

Eggs.-

Farinaccous.-Wheaten bread, hominy, rice, toast, oatmeal, gruels, arrowroot, tapioca pudding, sago.

Vegetables (in plenty, well cooked).-The green sorts generally; spinach, summer or green cabbage, turnip tops, mushrooms, celery, salads, rhubarb, cresses, lettuce, onions.

Dessert.-Milk and rice puddings, stewed fruits, raw fruits (especially laxative), fruit jelly.

Beverages. - Weak tea, peptonized milk, plenty of pure water, milk, koumiss, barley-water, hot water an hour before meals, buttermilk, Bordeaux, and seltzer. Mineral Waters-Bethesda, Clysmic, Berkeley, Gettysburg, Poland, Highland Spring, Vittel, Wildungen, Vals, Bath.

Stimulants.-

\section{Must AvoID:}

Soups, fried fish, cooked oysters, beef, mutton, lamb, corned beef, real, turkey, hashes, stews, made dishes, sauces, spices, potatoes, peas, beans, lentils, pies, pastry, cheese, new bread, cakes, ices, sweets, coffee, tobacco, malt liquors, spirituous liquors.

\section{AN}

General Rules.

Generous, nutritious diet is important. Readily-digested food should be given often and in small quantities.

\section{MaY TAKE:}

Soups.-Broths, all kinds. May add macaroni or vermicelli. Thick soups. 
Fish.-All fresh fish, raw oysters.

Meats. - Chopped or scraped, raw or rare, mixed with broths, chocolate, or Burgundy and water, or made into sandwiches. Ham, broiled bacon, beef-juice, mutton, chicken, game, cod-liver oil as food, butter plentifully, Mosquera's beef-meal.

Eggs.-Soft-boiled, poached, scrambled, raw beaten up with sherry or with whiskey.

Farinaceous (give in plenty unless indigestion).-Bread, cakes, tapioca, sago, groats, barley, hominy, cracked wheat, graham grits, rolled oats, rolled rye, corn meal, malt extracts.

Vegetables.-Most kinds, well boiled or as purées.

Dessert.-Sweet fruits, custards, calf's-foot jelly, fruit jam, jellies, baked apples, baked pears, prunes, marmalade, egg-and-milk pudding.

Beverages.-Carbonic water, ozonized water, milk, cream, chocolate, cocoa, peptonized milk, malted milk, koumiss, kefyr. Mineral WatersPoland, Highland Spring, Oak Orchard, Richfield, Sharon, White Sulphur, Saratoga, Homburg, Kissingen, Royat, Bath, Vichy, Apollinaris.

\section{Stimulants.-}

\section{MUST AVOID:}

Pork, veal, greasy hashes, salt meat, except ham; made dishes, thin soups, cabbage, cucumbers, turnips, carrots, squash, pickles, spices, pies, pastry, pineapple, bananas.

\section{CONSTIPATION}

General Roles.

Use foods that leave a bulky residue to stimulate the muscular coat of the intestines.

\section{MAY TAKE:}

Soups.-Broths, oyster soup, sorrel soup.

F'ish.-All kinds boiled. White sorts broiled. Sardines in oil.

Meats.-Most kinds, poultry, game, etc.

Farinaceous.-Brown or graham bread, gingerbread, oatmeal porridge, bran bread, bran pudding, wholemeal bread, corn bread.

Vegetables.-Most fresh varieties, well boiled. Spinach, boiled onions, brussels sprouts, cauliflower, salads with oil, lettuce, asparagus, tomatoes, salsify, celery.

Dessert.-Figs, prunes, tamarinds, baked apples, oranges (on rising), melons, grapes, raisins, stewed fruits, honey or treacle.

Beverages. - Glass of water, preferably hot, drunk on rising (add salt to taste). Pure water in plenty, black coffee, cocoa, lemonade, beer, ale. Mineral Waters-Richfield Springs, Crab Orchard, Bedford, Sara- 
toga, Hunyadi, Carlsbad, Rubinat, Friedrichshall, Kissingen, Villacabras, Puellna.

Stimulants.-

\section{Must AVoID:}

Pork, veal, goose, liver, hard-boiled eggs, salt meats, salt fish, peas, beans, nuts, pineapples, new bread, pastry, pickles, cheese, spirituous liquors, milk.

\section{DIABETES}

\section{General Rules.}

Reduce to a minimum all starches and sugars. Increase animal diet and fats. Avoid eating any starchy or sugary condiments to foods. Drink water freely to eliminate sugar. Substitute saccharin for sugar.

\section{May take:}

Soups.-Consommé of beef, veal, chicken, turtle, terrapin, oyster, and clam without flour. Chowder without potatoes; mock turtle, mullagatawny, tomato, gumbo fillet.

Fish.-All kinds; lobster, oysters, clams, terrapin, shrimp, crawfish, soft-shell crabs. No sauces containing flour.

Meats.-Preferably fat. Cooked in any way except with flour. Poultry, calf's head, kidneys, sweetbread, ham, tongue, sausage, hash (without potatoes), pig's feet, tripe, eggs, all kinds of game (not breaded).

Relishes.-Pickles, radishes, sardines, anchovies, celery, olives.

Farinaceous.-Gluten bread, gluten gems, gluten porridge, fried gluten mush, gluten wafers, gluten griddle-cakes, almond bread and cakes, charred bread, bran cakes, soya bread. May substitute potatoes for bread. Substitute gluten for flour in soups and gravies.

Vegetables.-Truffles, lettuce, romaine, chickory, cucumbers, spinach, sorrel, beef-tops, cauliflower, cabbage, brussels sprouts, dandelions, tomatoes, oyster plant, onions, string beans, watercresses, asparagus, artichoke, parsley, mushrooms; all kinds of herbs; sauerkraut.

Dessert.-Almonds, hazelnuts, walnuts, cocoanuts, acid fruits, lemons, currants, cream custards, cheese, jellics, and ice-cream sweetened with saccharin or glycerin. In cooking acid fruits neutralize acidity with bicarbonate of soda or potash.

Beverages.-Tea and coffee without cream or sugar, buttermilk, koumiss, skim-milk, plain soda, red wine, dry sherry, Bass' ale or bitter beer, claret, Burgundy. Ail in moderation. Mineral Waters-Alkaline and alkaline calcic, Saratoga, Waukesha, Bcthesda, Poland, Highland 
Spring, Londonderry Lithia, Buffalo Lithia, Hudor Lithia, Aquzon, Vichy, A pollinaris, Carlsbad, Ems, Marienbad.

Stimulants.-

Must avoid:

Livcr, wheat bread, corn flour, rice, sago, arrowroot, barley, oatmeal, tapioca, macaroni, puddings, beet-root, sweet vegetables, potatoes, carrots, peas, beans, parsnips, turnips, all sweet fruits, apples, pears, plums, grapes, oranges, apricots, peaches, gooseberries, dates, watermelon, sweet wines, cordials, portcr, lager beer, cider, mustard, honcy, sweets, ices, jams, treacle.

Receipts for Use of Gluten Flour.

Gluten Bread.-Less yeast is required than with starch flour, and less time in the raising process; very sour or old yeast should never be used. Take one quart of sweet milk or milk and water, one heaping teaspoonful of good butter, one-half cake of any fresh dry hop yeast, or onefifth of a two-cent cake of compressed yeast, beaten up with a little water, and two eggs, well beaten. Stir in gluten till a soft dough is formedabout the consistency of a baking-powder biscuit. Put in pans to raise, and when light bake in a hot oven.

Gluten Griddle-Cakes.-For two persons beat up nicely one egg, add a pint of water, a little salt, and stir in gluten to make a batter, much thicker than wheat flour griddle-cake batter is usually made. Previous to adding the gluten, mix with it thoroughly a slightly hcaped tablespoonful of baking-powder. Stir in two or three ounces of good butter.

Gluten Gems.-Put the batter prepared as above into very hot, wellbuttered gem-pans, and bake without burning in quick oven. It takes somewhat longer to bake these than other gems.

Two, Two, Two Gems.- Stir two cups of gluten, two eggs, and a trifle of salt into two large cups of sweet milk or cream. Beat all well together, pour into very hot gem-pans, and bake in quick oven.

Gluten Porridge is made by stirring the gluten into boiling water until thick cnough, and then keeping up the boiling process for fifteen minutes. A little salt and butter are added at the close to improve the flavor, and it may be catcn with milk or crcan.

Gluten Cream Wafers.-Stir gluten (crude or purified) into sweet cream until the dough is thick enough to roll out to the thickness of pasteboard. A little salt may be added if desired. Cut in any form and bake to a delicate brown.

For Soups and Gravies.-Gluten is better than flour. It is frequently delicately browned for these purposes.

Biscuit of Bran Flour.-To one-quarter of a pound of flour add three or four frcsh eggs, one and a half ounces of butter, and half a pint 
of milk; mix the eggs with a little of the milk, and warm the butter with the other portion; then stir the whole together well; add a little nutmeg or ginger or other agreeable flavoring, and bake in small forms or patterns. The cake, when baked, should be about the thickness of an ordinary captain's biscuit. The pans must be well buttered. Bake in rather a quick oven for half an hour. These cakes or biscuits may be eaten with meat or cheese for breakfast, dinner, or supper; at tea they require rather a free allowance of butter, or they may be eaten with curd or any soft cheese.

\section{DIARRHCEA}

General Rules.

Avoid foods that ferment easily and those that leave an undigested residue behind, thus causing intestinal irritation. Take food in small quantities and at regular intervals.

Soups.-Milk soup.

\section{MAY TAKE:}

Meats.-Scraped beef or mutton, pounded raw meat, sweetbread, beef-juice, liquid peptonoids, Mosquera's beef-meal.

Eggs.-Raw white of egg with water, lightly boiled, poached.

Farinaceous.-Crackers, toast, macaroni, rice boiled with milk, arrowroot, tapioca, sago, gruel boiled for two or three hours, flour-ball boiled for two or three hours with milk. May add brandy or port wine to arrowroot or gruel.

Dessert.-Milk foods, milk, egg pudding not sweet, hasty pudding with flour and milk.

Beverages.—Sterilized or pasteurized milk, skim-milk, milk with lime-water, peptonized milk, strong tea, lactic-acid water, toast-water, rice-water, koumiss, egg lemonade. Mineral Waters-Alleghany Springs, Berkeley Springs, Bethesda Springs, Gettysburg Springs, Vittel, Wildungen, Bristol.

Stimulants.-

\section{MusT AVOID:}

Vegetables, soups, new bread, brown and graham bread, oatmeal, fruits cooked or raw, fried foods, fish, sugary foods, made dishes, nuts, salt meats, veal, pork.

\section{DYSPEPSIA}

General Rules.

Small meals taken at regular iniervals. Punctuality is of great importance. Masticate thoroughly; eat slowly and temperately. 


\section{MAY TAKE:}

Soups.-Small quantity. Clear soups of beef, mutton, oyster. A little vermicelli or tapioca may be boiled with these. Cream pea soup, pea and tomato soup, hominy and bean soup.

Fish-Oysters and little-neck clams in any form except fried. Weak fish, white fish, shad, cod, perch, trout, bass, smelt, fresh mackerel.

Meats.-Meat-juice, roast or broiled becf, mutton, chicken, tripc, calf's head, vcnison, tongue, sweetbread.

Eggs.--Raw, soft-boiled, poached, omelctte, combined with chicken or oysters; eat dry toast or stale brcad with cggs.

Farinaceous.-Bread at least one day old; brown bread, toast, rye, gluten, and graham bread, zwieback, crackers, cream crackers, cracked wheat, rice, sago, tapioca, macaroni, arrowroot, corn meal, hominy, wheaten grits, graham grits, vermicelli, rolled rye, rolled oats, rice cakes, browned rice, baked flour.

Vegetables (best made into purée by passing through a colander or mashing).-Grcens, spinach, lettuce, water-cresses, French beans, sweet corn, green peas, asparagus, celery, artichokes, baked tomatoes, potatoes (but little).

Dessert.-Fruit, rice, tapioca, Indian, and farina puddings, custards (rice, snow, rennet, sponge cake, floating island), orange charlotte, gelatin creams, blanc mange, baked and stewed apples and pears, grapes, and all ripe fruits except bananas and pineapples. No rich sauces.

Beverages (drinks should mostly be taken near the end of meals).Hot water beforc meals, milk, lime-water, Vichy, weak tea (one-half ounce to the pint), koumiss, weak cocoa, pcptonized cocoa and milk, buttermilk, acid wine, if acidity. Black coffee and lemon-juice on first rising. Mineral Waters-Carbonic water, Congress, Hathorne, Ballston, Kissingen, Apollinaris, Poland, Highland Spring.

Stimulants.-

\section{MUsT AVOID:}

Rich soups and chowders, all fried foods, veal, pork, liver, kidney, hashes, stews, pickled and corned meats, preserved and potted meats, turkey, goose, duck, sausage, salmon, salt mackerel, bluefish, sturgeon, eels, shrimps, sardines, lobster, crabs, cabbage, cauliflower, cucumbers, string beans, parsnips, egg plant, turnips, carrots, squash, oyster plant, sweet potatoes, beets, pastry, pies, made dishes, nuts, dates, jams, dried and candied fruits, candies, cheese, strong tea, ice-water, malt liquors, sweet and effervescent wines, spirituous liquors. 


\section{FEVERS}

General Rules.

Mostly liquids in small quantities and often; partially digested food; never give anything that cannot pass through the fine mesh of a sieve; give more in the morning than in the evening. Loss of appetite should be respected in the acute stage. Utilize periods of remission.

\section{MaY TAKE:}

Soups.-Raw-meat juice, clam broth, chicken broth, vegetable broths, mutton broth, broth with egg, broth of gelatin, beef-tea, clear soups, fruit soup.

Eggs.-Beaten up with water or stimulants.

Foods.-Peptonized milk, malted milk, Mellin's food, Nestle's food, liquid peptonoids, flour-ball with milk, milk toast, arrowroot, Indian meal gruel, oatmeal gruel, ground rice, Mosquera's beef-meal, pounded raw meat, oysters; in convalescence meat and calf's-foot jellies.

Beverages.-Skim-milk alone (one and one-half quarts to two and one-half quarts in twenty-four hours), buttermilk, whey, koumiss, barleywater, rice-water, toast-water, jelly-water, gum-arabic water, plain soda, lemonade, fruit juices, egg lemonade, eggnog, cocoa. Mineral WatersCarbonic water, ozonized water, Vichy, Apollinaris, Seltzer, Poland, Highland Spring.

Stimulants.-

\section{Must AVOID:}

All solid foods until the temperature has remained normal for days.

\section{GOUT OR URIC ACID DIATHESIS}

\section{General Rules.}

Diet liberal, but not stimulating; moderation in animal foods; guard against foods having a tendency to produce acid in the system, such as starches, sugars, fats, and fermented liquors.

\section{MAY TAKE:}

Soups.-Clear soups, vegetable soups, weak beef-tea, broths.

Fish.-Fresh fish, raw oysters.

Meats (to be taken once a day only, white kinds mostly).--Mutton, chicken, ham, bacon, underdone roasts, sweetbread, pigeon, brains, pigs' feet, venison.

Eggs (in moderation).-Whites of eggs, raw, stirred in drinks.

Farinaceous (small quantities).-Toast, stale bread, bread from 
whole wheat, rye bread, milk toast, rice, zwieback, graham gems, graham flakes, rye gems, soup sticks, crackers, hominy.

Vegetables (fresh green varieties).-Celery, lettuce, watercress, cucumbers, onions, cabbage, salads, a little baked potato, young peas, string beans, spinach.

Dessert.-Oranges, lemons, cranberries, apples, apricots, pears, peaches, cherries, jellies, blanc mange, honey, ices (not after meals), stewed or roasted fruit.

Beverages.—Water plentifully, plain soda, milk, buttermilk, weak tea or coffee (no sugar), toast-water, lime-juice, lemonade. Mineral Waters-Saratoga Vichy, Berkeley Hot Springs, Virginia, Lithia Waters, Crab Orchard, Bethesda, Carlsbad, Friedrichshall, Puellna, Villacabras, Marienbad.

Stimulants.-Moselle, light Hock, Bordeaux in small quantities and diluted.

\section{Must AvoID :}

Rich soups, hard-boiled eggs, fried and made dishes, entrées, pickles, spices, veal, turkey, duck, goose, salmon, lobster, crab, preserved, dried, and salt meats, salt fish, pickled pork, asparagus, peas, beans, tomatoes, mushrooms, truffles, dried fruits, preserves, pies, pastry, rich puddings, patties, new bread, cheese, sweets, omelettes, sweet wines, strawberries, rhubarb, cider, fermented drinks, beer.

\section{OBESITY}

Generat Rules.

Avoid sugars, starches, and excess of fat-forming foods. A certain amount of fat with the food is essential.

\section{MAX TAKE:}

Soups (very little).-Chicken broth, oyster soup, clam broth, thin beef-tea.

Fish.-All kinds except salt varieties, salmon or bluefish.

Meats (once a day only).-Lean beef, mutton, chicken, game.

Eggs.-Boiled and poached.

Farinaceous.-A limited amount of dry toast, gluten biscuits, beaten biscuits, zwieback, Vienna rolls, soup sticks, crusts, graham gems, hoecakes.

Vegetables (fresh).-Asparagus, celery, cresses, cauliflower, greens, spinach, lettuce, white cabbage, tomatoes, radish, very little, if any, potatoes. fruits.

Dessert.-Grapes, oranges, cherries, apples, peaches, berries, acid 
Beverages.-Limited quantity of water, tea, coffee (no sugar or milk), light wine diluted with Vichy. Mineral Waters-Avon Springs, Richfield Springs, Crab Orchard, Londonderry Lithia, Hunyadi, Carlsbad, Friedrichshall, Rubinat, Puellna, Villacabras.

\section{Must AVOrD:}

Fats in excess, beverages in excess, thick soups, salmon, bluefish, eels, herrings, salt fish, pork, veal, sausage, spices, hominy, oatmeal, macaroni, potatoes, parsnips, turnips, carrots, beet-root, rice, currants, puddings, pies, cakes, sweets, milk, sugar, malt and spirituous liquors.

\section{Schemes of Meals. \\ EBSTEIN.}

Breakfast.-One cup of black tea. Two ounces buttered toast.

Dinner (at noon).-Shinbone soup. Four to six ounces of well boiled or roasted fat meat with gravy. Peas, beans, cabbage, in moderation. Salads, fresh fruits or dried fruits with sugar. Moderate amount of black tea and light wine.

Supper.-One cup of black tea. One egg or fish (may substitute ham or other fat meat). One onnce of well-buttered bread. A little cheese and fresh fruit.

\section{DUJARDIN-BEAUMETZ.}

Breakfast.-Bread-crust, three-fourths of an ounce. Cold meat, one and a half ounces. One cup weak tea, without sugar.

Luncheon.-Bread, one and a half ounces. Meat, three ounces, or two eggs. Fresh vegetables, three ounces. Salads, cheese, one-half ounce. Fruit to taste.

Dinner (in the evening, no soup).--Similar to lunch, plus bread one and three-fourths ounces, meat three ounces.

\section{S. WEIR MITCHELL.}

Milk eight ounces and one egg every three hours (when awake) for twenty days; no other food or drink; then gradually enlarge dietary.

\section{TUBERCULOSIS}

General Rules.

Eat as much as can possibly be digested, mostly fatty and nitrogenous foods. It is important to take food between meals and before going to bed. Do not have meals more than three hours apart. 


\section{MaY TAKE:}

Soups.-Bouillon, clam broth, chicken broth, mutton broth, barley, rice, bean and pea broth, beef-juice and tea, oyster soup, turtle soup.

Fish.-Fresh fish, codfish, raw oysters.

Meats.-Beef raw, underdone, scraped or pounded; roast mutton, lamb chops, poultry, game, bacon, ham, swcetbread, Mosquera's beefmeal, beef-juice, liquid peptonoids.

Eggs.-All ways but fried. Bcat with milk, whiskcy, or sherry.

Farinaceous. - What bread, Indian-meal bread, with plenty of butter, oatmeal, malt extracts.

Vegetables.-Onions, tomatoes, string beans, spinach, asparagus, lettuce, cresses, celery, greens, peas, rice well cooked.

Fats and Oils.-Mutton, bcef, butter, cream, olive and cod-liver oil.

Dessert.-Tapioca and sago puddings, farina, floating island, custards, all fruits, cheese, butter-scotch.

Beverages.-Ozonized water, carbonized water, hot water or hot Vichy water (one pint an lour before meals), lemonade, ginger ale, malt preparations, milk, cream, koumiss, cocoa, ehocolate. Mineral WatersAlkaline, iron, and sulphur. Oak Orchard Springs, Richfield Springs, Lower Blue Lick, Grcen Brier, White Sulphur Springs, Red Sulphur Springs, Aix la Chapelle, Homburg, Franzensbad, Cheltenham.

\section{MUsT AVoID:}

The excessive use of farinaceous, sugary, or starchy foods; pork, veal, hashes, salt fish, lobster, bluefish, turnips, beets, potatoes, cucumbers, cabbage, parsnips, carrots, macaroni, sphaghetti, arrowroot, cornstarch, hot bread and cakc, all fried foods, made dishes, gravies, sweets, pies, and pastry.

\section{PRIVATE NURSING, FROM A NURSE'S POINT OF VIEW}

\section{BY JOSEPHINE HILL}

THERE is so much to be said on the subject of private nursing, and so many sides from which it may be viewed, that I will leave untouched all sides except that of a happy relation between patient and nurse. All well-trained nurses know, of course, what is necessary to do or not to do in the sick-room, so it is not the nurse professionally with whom I am talking, but the woman individually. I think that to win the confidence, and even the affection, of a sick person, is equally as important as fulfilling 